\title{
Slope steepening of the Golden Pike west wall at Fimiston Pit
}

\author{
GP Bungard Kalgoorlie Consolidated Gold Mines, Australia
}

A Gleeson Kalgoorlie Consolidated Gold Mines, Australia

FRP Basson Newmont Mining Corporation, Australia

\begin{abstract}
Kalgoorlie Consolidated Gold Mines (KCGM) has recently completed a slope optimisation study to safely steepen the western wall of the Golden Pike cutback. The optimised slope design exceeds $700 \mathrm{~m}$ in height, with a maximum overall slope angle of $52^{\circ}$, putting it near the limit of global experience. To build a case for a steeper slope design, KCGM undertook a campaign of data collection and analysis, which culminated in the successful completion of batter steepening trials within selected geotechnical domains. The optimised design incorporates a $75 / 90^{\circ}$ bi-angle batter face, to achieve steeper inter-ramp slopes while maintaining sufficient berm catch capacity. This paper summarises the work undertaken to support the steepened slope design and the future geotechnical engineering inputs required for successful completion.
\end{abstract}

\section{Introduction}

This paper discusses the outcomes of a geotechnical project that was undertaken to optimise slope angles on the Golden Pike west wall, which also supported the mining of steeper fresh rock slopes within selected geotechnical domains. The project was undertaken over a two and a half year period and involved a comprehensive geotechnical data collection, implementation and slope performance monitoring program. The data collection and performance monitoring program aimed to validate and supplement the already extensive geotechnical database compiled during the feasibility study. This dataset consisted mainly of core logging data in the regions of the Golden Pike slope, but also included face mapping data from previous mining phases. The following data collection was undertaken during the project:

- Geotechnical data collection:

- Face mapping to characterise structures and determine the rock mass fabric.

- Photogrammetry mapping to collect rock mass structural orientation and persistence data and aid with the mapping of continuous structures.

- Implementation performance monitoring:

- Reconciliation of as-built batter berms against designed berms to measure the effectiveness of the design implementation across varying structural domains or slope sectors and with varying blasting practices.

- Face evaluations to measure the effectiveness of blasting and scaling practices.

- Ground support (cable bolt) usage across different batter configurations.

- Downhole bore track surveys to measure presplit downhole deviation.

- Slope performance monitoring:

○ Prism monitoring to track long-term slope displacement.

- Radar monitoring to identify and track the short-term slope response to blasting, excavation and rainfall events. 
- Rockfall database records to allow the identification of rockfall source areas, trigger events, rockfall catch effectiveness and trends.

- Groundwater monitoring using standpipes and vibrating wire piezometers (VWP) to track the response of pore pressures behind the pit slope in response to mine dewatering and significant rainfall events.

- Microseismic monitoring to measure the rock mass response to mining.

The geotechnical structural data collected largely validated the original geotechnical database. Both the structural data collected and the slope performance monitoring results, supported slope steepening, however, the implementation performance data did not. The main challenge had been the substandard berm widths as a combined result of excessive toe flare and crest loss. These problems were overcome through improved drilling, blasting and scaling practices, as well as the introduction of a $75 / 90^{\circ}$ bi-angle batter design.

Batter steepening trials were conducted within selected geotechnical domains over two $30 \mathrm{~m}$ batter stacks. A review of these trial batters showed the performance comparable or better than the original design. The $20 \mathrm{~m}$ vertical presplit holes were drilled with less downhole deviation, leading to a reduction in batter face flare. Kalgoorlie Consolidated Gold Mines (KCGM) also replaced its top hammer presplit drill rigs with down the hole hammer rigs, which also reduced downhole deviation.

Numerical modelling demonstrated that the revised life-of-mine (LOM) design incorporating the steepened bi-angle batters, met the mine owner's acceptance criteria. The steeper design required a ramp reconfiguration and added approximately 630,000 ounces to the LOM reserves and 12 months to mine life.

\section{$1.1 \quad$ Overview of Fimiston Pit}

The Fimiston Pit (informally known as the Superpit) is located immediately east of the city of Kalgoorlie-Boulder and approximately $600 \mathrm{~km}$ east of Perth, Western Australia. Mining of the Fimiston Pit commenced in 1989 and followed almost a century of intensive underground exploitation extending to a maximum depth of $1,300 \mathrm{~m}$. These historic underground workings require rigorous controls to maintain safe working conditions on the pit floor.

The current pit dimensions are approximately $3.5 \mathrm{~km}$ long, $1.5 \mathrm{~km}$ wide and $550 \mathrm{~m}$ deep. The Golden Pike cutback currently being mined will extend the ultimate pit depth to $720 \mathrm{~m}$ when completed in 2020 . The Fimiston operation currently extracts about 700,000 ounces of gold per year.

\subsection{Local geology}

Geology of the Fimiston deposit has been described by Clout et al. (1990), and the description of the geology in this section has been sourced from this work. The Kalgoorlie Goldfields are situated within a north-northwest striking Archean greenstone belt running between Norseman and Wiluna. The succession consists of a 3,000-4,000 m thick sequence of volcano-sedimentary rocks regionally metamorphosed to grades varying from lower greenschist to amphibolite rank. The gold deposits are mainly hosted by the mafic and ultramafic units. Within the Fimiston Pit the following stratigraphic units are present:

- Golden Mile Dolerite (GMD): a differentiated gabbroic (tholeiitic) sill, subdivided into 10 sub units based on mineralogy.

- Paringa Basalt (PB): pillowed to massive basalt flows with minor interflow sediments.

- Black Flag Beds (BFB): thick sequence of sediments and felsic volcanics.

- Porphyry Dykes: minor (0.5-10 m wide) late porphyritic intrusions that cross-cut all other units. 
The depth of the oxide profile varies across the Fimiston Pit between approximately 40and $130 \mathrm{~m}$, with deeper sections associated with paleochannels. The distribution of these main units on the Golden Pike west wall is shown in Figure 1.

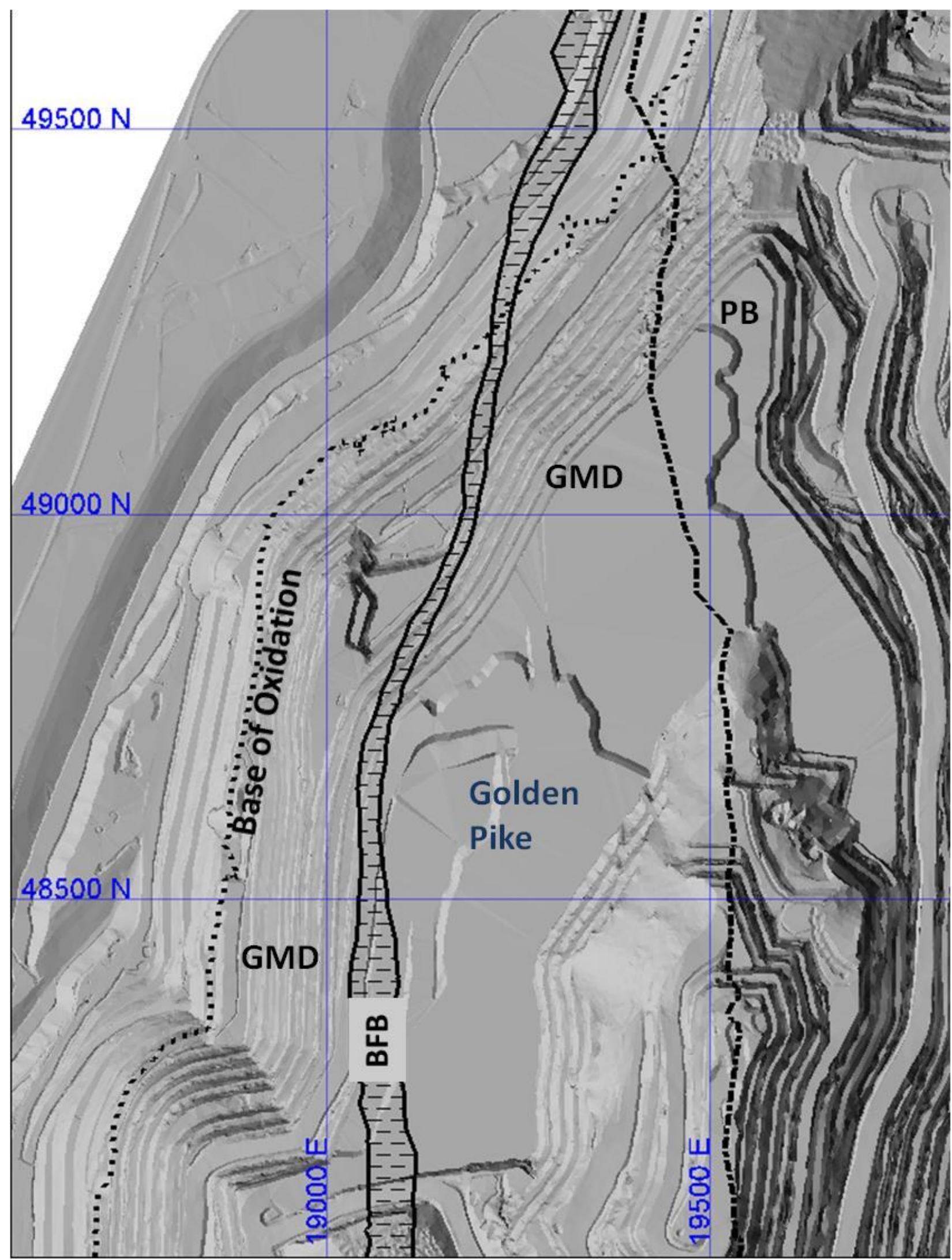

Figure 1 Distribution of geological units on the Golden Pike west wall 


\subsection{Hydrogeology and pit dewatering}

The Fimiston Pit can be described as a dry mine, as the underground workings have provided an efficient drainage network that was dewatered for underground mining prior to the existence of the Fimiston Pit. The interconnected workings allow for dewatering of the entire pit footprint to be undertaken from a single dewatering pump. Dewatering operations aim to maintain a water level beneath that of the planned pit design.

Behind the pit slopes and beyond the influence of underground mining voids, a steep groundwater draw down surface exists, due to the low permeability of the rock mass. Groundwater pore pressures are monitored through a network of nested VWPs and open standpipes installed behind the pit slopes.

\subsection{Geotechnical input to mining at Fimiston}

Fimiston Pit, being a large deep pit with highly optimised slopes, requires significant geotechnical input to implement slopes in a safe, responsible and efficient manner. Mining operations are very reliant on slope stability monitoring to demonstrate stability of slopes and provide advance warning of developing instability. The KCGM geotechnical team operates two slope stability radars and monitor the east and west walls simultaneously. Both radars have geotechnical alarms that trigger when exceeding site-specific velocity thresholds, and are monitored through the pit dispatch office. Four automated prism monitoring stations provide daily monitoring data on approximately 400 prisms to track long-term slope performance.

\subsection{Project background}

KCGM has a long history of slope optimisation resulting from having a deep pit, steeply dipping orebody, and established infrastructure located closely behind the east and west pit crests. An in-house slope optimisation study for the east wall was completed during 2009, the first stage of this study was published for the 2007 Slope Stability Conference (Beer \& Morrongiello 2007).

The Golden Pike west wall feasibility study was completed during 2010 and the slope design parameters, shown in Table 1, were determined for all of the geotechnical domains. The potential to steepen slopes within the GMD was recognised, however, the study concluded that further structural data had to be collected, and the performance of trial slopes mined to these parameters be assessed. The potential to steepen slopes within PB was considered, but with limited exposure on the west wall, this option provided limited upside. Steepening was not considered within the BFB due to their weaker rock mass strength.

Table 1 West wall feasibility slope design parameters

\begin{tabular}{|c|c|c|c|c|}
\hline Domain rock type & $\operatorname{BFA}\left({ }^{\circ}\right)$ & $\mathrm{BH}(\mathrm{m})$ & $B W(m)$ & $\operatorname{IRA}\left({ }^{\circ}\right)$ \\
\hline Weathered/oxide & 50 & $20(2 \times 10)$ & 10 & 37 \\
\hline GMD & 75 & $30(3 \times 10)$ & 10 & 59 \\
\hline PB & 75 & $30(3 \times 10)$ & 10 & 59 \\
\hline BFB & 75 & $30(3 \times 10)$ & 10 & 59 \\
\hline
\end{tabular}

BFA - Batter Face Angle; BH - Batter Height; BW - Berm Width; IRA - Inter-ramp Angle

A geotechnical project team was formed in late 2012 and tasked with undertaking the data collection and analysis program. The team consisted of a senior and a project geotechnical engineer.

\section{Data collection}

The following subsections focus on aspects of geotechnical data collection and slope monitoring performance. 


\section{$2.1 \quad$ Structural model}

Structural data collection consisted of regular scanline face mapping and photogrammetric mapping. Face mapping identified and provided characterisation data on major structures and rock mass fabric. It was not possible to cover all areas with field mapping due to restricted access from underground workings beneath the pit floor, and the rate of wall turn over. The focus was rather on regularly collecting representative data and validating the photogrammetric data against field measurements. Field mapping utilised a scanline approach, collecting all intersecting structures exceeding a lower persistence cutoff of $5 \mathrm{~m}$. Photogrammetric mapping was undertaken for $100 \%$ of exposed slopes, and was undertaken on the completion of each $30 \mathrm{~m}$ batter face. Photogrammetric mapping allowed for the collection of data from a much wider coverage area and a higher density of mapping data on both new and existing slopes. The photogrammetric models were particularly useful for developing major structural models and providing persistence data for each set.

Mapping confirmed that the major structural framework exposed on the Golden Pike west wall consists of:

- North-northeast - south-southwest trending and moderately west dipping structures (Golden Pike and Drysdale Faults).

- North-south trending sub-vertical faults (Mainlode Fault).

No other structures of continuity on the scale of the Golden Pike cutback were identified. However, an additional 75 intermediate scale (persisting across multiple batter faces) structures were identified and incorporated into the structural model. These intermediate structures form the following sets:

- North-south trending sub-vertical steeply west dipping faults. Undulating and anatomising brittle faults with generally clean rough surfaces.

- Northeast-southwest trending and sub-vertical dipping faults. Brittle distinct faults with clean rough surfaces, occurring infrequently.

- East-northeast-west-southwest trending and steeply southeast dipping faults. These are brittle persistent structures that occur as distinct clean, tight and undulating surfaces. Surfaces are typically undulating and rough.

- East-southeast-west-northwest trending and steeply south dipping faults. These are brittle persistent structures that occur as distinct clean tight surfaces with minor quartz infill. These structures tend to occur in localised swarms and sometimes produce a minor offset of other structural sets. Surfaces are typically rough and planar to undulating.

- Moderately southeast dipping joints. Infrequent and highly undulating joints with clean and rough surfaces and limited extent; often offset by other sets. These have formed basal sliding planes resulting in batter scale instability around the oxide - fresh transition. Within fresh GMD they have not resulted in instability to date, although they require cable bolting to secure leading edges.

Major structures are usually able to be identified within the drill core, however, intermediate structures are more difficult to identify. Extrapolation of these intermediate structures is based, in part, on the measured persistence on the pit wall or the persistence of other structures from the set, and structural cross cutting relationships between the structural sets as observed elsewhere in the pit. The intersection of these modelled intermediate and major structures against the Golden Pike west wall design are shown in Figure 2. 


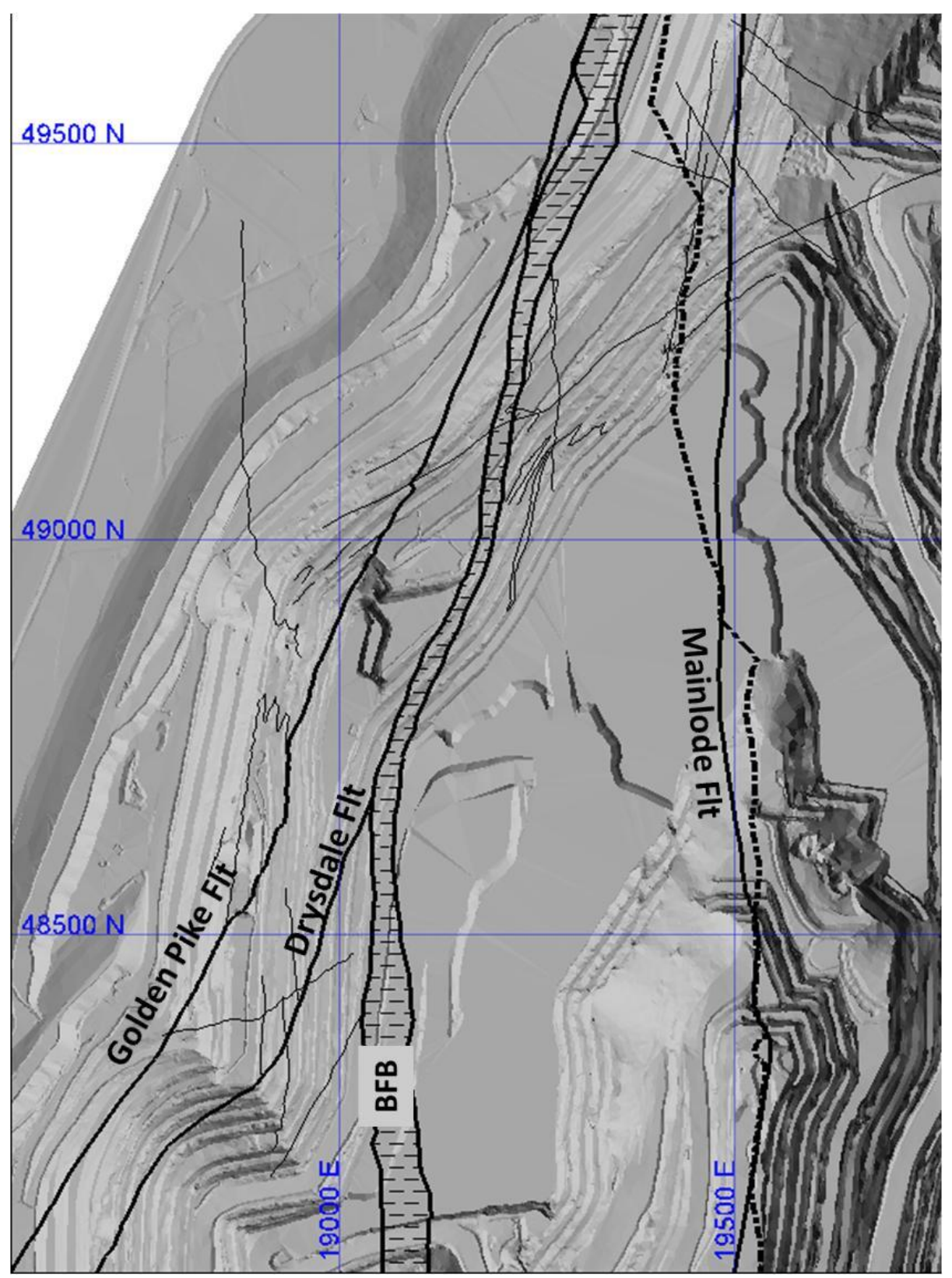

Figure 2 Modelled major and intermediate structural intersections on Golden Pike west wall

\subsection{Rock mass fabric characterisation}

GMD is characterised by the following structural concentrations of importance that could influence the stability of the west wall batter slopes:

- Disperse concentration of joints dipping moderately to steeply eastwards.

- Healed joints and veins dipping shallowly northeast.

- Joints dipping moderately north-northeast.

- Persistent joints dipping steeply northwards.

A summary of the rock mass structural sets is provided in Table 2 and the stereographic polar plot in Figure 3. The contouring in Figure 3 was computed using a count circle size of $1 \%$ of the hemisphere surface area. 
Table 2 Rock mass fabric character

\begin{tabular}{|c|c|c|c|c|c|}
\hline $\begin{array}{c}\text { Rock } \\
\text { mass set }\end{array}$ & $\begin{array}{c}\text { Mean } \\
\text { dip/dipdir }\end{array}$ & JRC & Persist (m) & Spacing $(\mathrm{m})$ & Description \\
\hline 1 & $67 / 111$ & $8-15$ & $5-30$ & $0.5-10$ & Clean rough undulating joints \\
\hline 2 & $38 / 054$ & $9-15$ & $5-40$ & $0.5-10$ & $\begin{array}{l}\text { Healed joints/veins } 0-10 \mathrm{~mm} \text { quartz } \\
\text { infill }\end{array}$ \\
\hline 3 & $54 / 018$ & $9-10$ & $5-25$ & $2-5$ & Clean or quartz healed joints \\
\hline 4 & $82 / 353$ & 9-15 & $5-30$ & $2-5$ & Clean rough planar joints \\
\hline
\end{tabular}

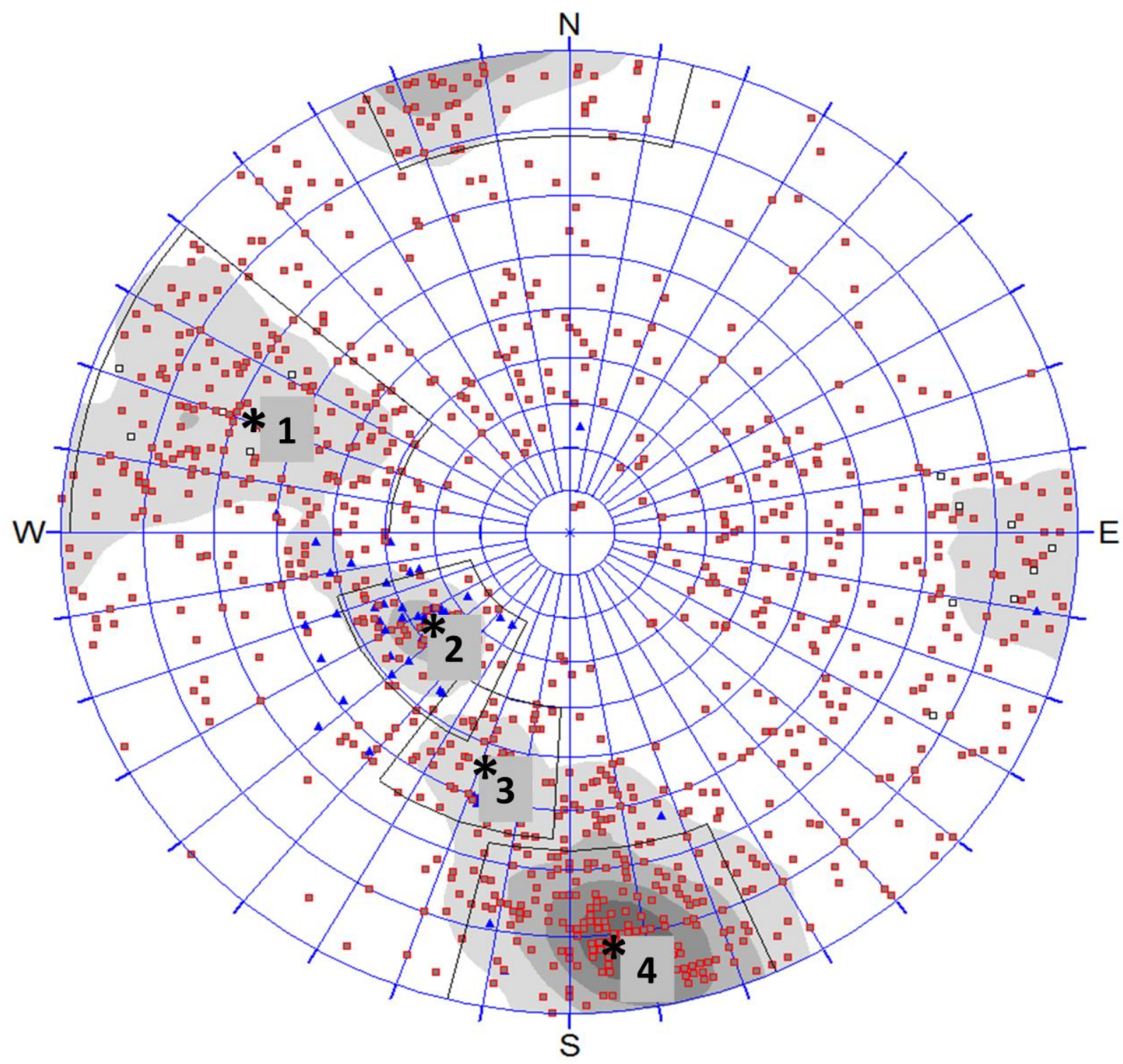

Figure 3 GMD mapping of joints (squares) and veins (triangles)

\subsection{Slope performance and monitoring trends}

The upper $180 \mathrm{~m}$ of fresh GMD was excavated without any occurrences of instability on batter or inter-ramp scale. Prisms are installed about mid height on every second $30 \mathrm{~m}$ batter face following excavation of the full batter; and are spaced at 50-100 m intervals along the wall. Prism measurement rounds are set to run four times daily and atmospheric corrections are applied based upon reference point measurements. 
Total three-dimensional displacements recorded on prisms installed within fresh GMD range between 30 and $40 \mathrm{~mm}$ for the 18 months since installation. These displacements are consistent with stable overall and inter-ramp slopes as supported by numerical modelling and previous experience from Fimiston Pit. Displacement tends to be most often triggered by adjacent wall blasting, and monitored and managed utilising the slope stability radar.

\section{Data analysis results}

The following subsections summarise work completed to support the implementation of batter steepening trials within GMD. A cumulative frequency analysis (CFA) was undertaken to assess the relative stability of steeper batter face angles, and the stability of inter-ramp and overall slopes were assessed by Itasca Australia Pty Ltd using 3DEC ${ }^{\mathrm{TM}}$ (Wines 2015). A statistical Probability of Failure (PF) was assessed using Phase $^{\mathrm{TM}}$ and Slide ${ }^{\mathrm{TM}}$ models and the response surface methodology (Wesseloo \& Read 2009).

\subsection{Cumulative frequency analysis}

The batter CFA was undertaken to assess planar and wedge modes of failure for various batter angle designs. The planar assessment utilised a $+/-30^{\circ}$ kinematic window and the wedge assessment a $+/-45^{\circ}$ kinematic window. Defect persistent data was used to limit the size of blocks and wedges that were generated and, therefore, the amount of crest loss sustained. The results of the CFA analysis for planar and wedge failure modes are summarised in Tables 3 and 4, respectively.

Table 3 CFA results for planar failure mode

\begin{tabular}{|c|c|c|c|c|c|}
\hline \multirow{2}{*}{$\begin{array}{l}\text { Sector Azimuth } \\
\left({ }^{\circ}\right)\end{array}$} & \multicolumn{5}{|c|}{ Probability of sliding for batter angles - planar failure mode } \\
\hline & $70^{\circ}$ & $75^{\circ}$ & $80^{\circ}$ & $85^{\circ}$ & $90^{\circ}$ \\
\hline 037 & $53 \%$ & $59 \%$ & $67 \%$ & $70 \%$ & $73 \%$ \\
\hline 065 & $49 \%$ & $52 \%$ & $57 \%$ & $64 \%$ & $69 \%$ \\
\hline 095 & $43 \%$ & $57 \%$ & $70 \%$ & $85 \%$ & $93 \%$ \\
\hline 120 & $37 \%$ & $53 \%$ & $66 \%$ & $83 \%$ & $91 \%$ \\
\hline 135 & $36 \%$ & $50 \%$ & $63 \%$ & $79 \%$ & $88 \%$ \\
\hline
\end{tabular}

Table 4 CFA results for wedge failure mode

\begin{tabular}{|c|c|c|c|c|c|}
\hline \multirow{2}{*}{$\begin{array}{l}\text { Sector Azimuth } \\
\left({ }^{\circ}\right)\end{array}$} & \multicolumn{5}{|c|}{ Probability of sliding for batter angles - wedge failure mode } \\
\hline & $70^{\circ}$ & $75^{\circ}$ & $80^{\circ}$ & $85^{\circ}$ & $90^{\circ}$ \\
\hline 037 & $34 \%$ & $42 \%$ & $48 \%$ & $51 \%$ & $52 \%$ \\
\hline 065 & $34 \%$ & $42 \%$ & $47 \%$ & $49 \%$ & $49 \%$ \\
\hline 095 & $12 \%$ & $13 \%$ & $14 \%$ & $14 \%$ & $15 \%$ \\
\hline 120 & $17 \%$ & $19 \%$ & $22 \%$ & $24 \%$ & $26 \%$ \\
\hline 135 & $24 \%$ & $30 \%$ & $34 \%$ & $38 \%$ & $40 \%$ \\
\hline
\end{tabular}

These results and observations, of an existing slope, show planar back break to be the dominant structural failure mode in all slope sectors. Back break due to wedge failure mode is negligible on east dipping slopes and has a secondary influence (to planar mode) on northeast and southeast dipping slopes. The planar analysis results, along with orientation and persistence data, were used to predict crest back break curves 
for each batter face angle. These curves were calibrated to measured crest loss levels on existing $75^{\circ}$ batter faces. The calibrated curves are presented in Figure 4.

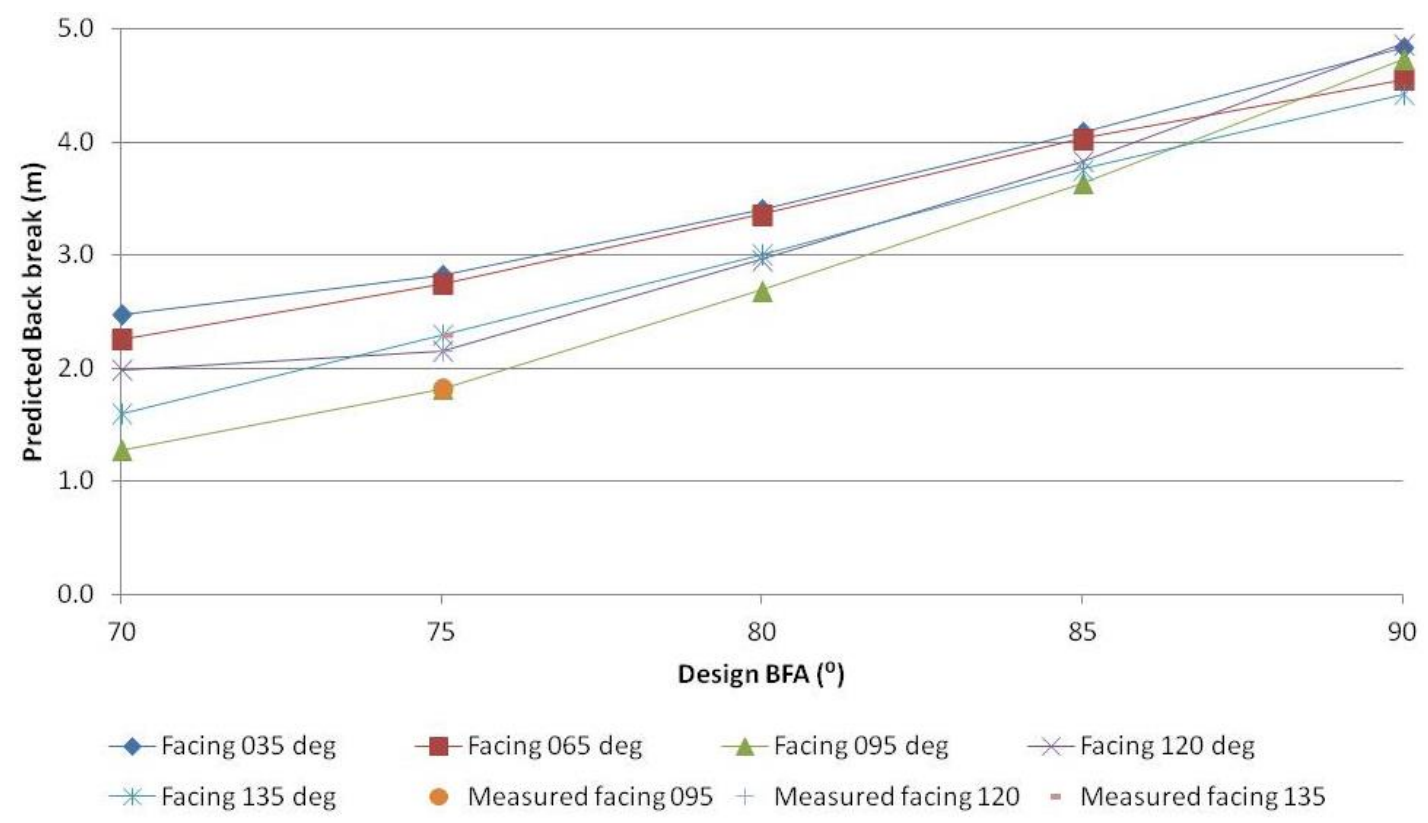

Figure 4 Calibrated 50th percentile back break predictions

Steepening of the $75^{\circ}$ base case batter angle to $80^{\circ}$ would incur a modest increase in back break from a 50th percentile of approximately 2.2 to $3.0 \mathrm{~m}$, across all sectors. This increase was considered tolerable for an $80^{\circ}$ batter, however, it was considered more practical to trial a bi-angle batter face maintaining the upper $10 \mathrm{~m}$ at $75^{\circ}$.

\subsection{Slope stability analysis}

The stability of the steeper design was assessed using 3DEC (Wines 2015). Three-dimensional analyses were performed for the Golden Pike west wall with major faults and remnant stopes explicitly defined in the models. The base case model was represented by the best estimate of the rock mass strength, fault properties and phreatic surface. The modelled displacements were calibrated against prism displacement data obtained from Golden Pike and previous west wall cutbacks. The following conclusions were made based on the analysis (Wines 2015):

- The model provides a reasonable representation of the actual slope behaviour at the current excavation stage. A favourable correlation was achieved between modelled and monitored displacements.

- No areas of medium or large scale instability developed within the model, however, minor rock mass damage is predicted in localised areas around remnant stoping.

- Strength reduction analysis performed with a reduction factor of 1.5 identified no inter-ramp or overall slope instability, indicating the Factor of Safety (FS) predicted for all inter-ramp and overall final slopes is greater than 1.5.

\subsection{Response surface analysis}

An assessment of the PF was conducted for the critical overall slopes of the west wall. The PF of the most critical sections through the overall slope of the west wall was assessed by KCGM using Phase 2 and Slide to run deterministic models and using the response surface method (Wesseloo \& Read 2009).

Phase 2 models were run to test the actual FS using best estimate parameters. This model predicts a critical strength reduction factor of 1.7 for the steepened design compared to 2.4 for the original design. 
Slide models were constructed to test the influence of UCS, GSI, disturbance, groundwater level, and geological contact positions on FS. The best estimate deterministic Slide model for the steeper design, assuming a non-circular failure mechanism, predicts a slightly higher FS (1.9) than the Phase2 model and a similar failure path. For the original design critical section, the FS predicted by Slide was slightly lower than that predicted by Phase2 at 2.2.

The surface response is estimated by assessing the uncertainty in each parameter, by varying each selected variable in turn while the others are fixed at their best estimate value. A lower and upper bound case are assessed for each parameter. A second order polynomial is fitted to the normalised lower bound, best estimate, and upper bound values of each parameter. A modified FS can then be calculated by applying modification factors (B values) to the best estimate FS using Equation 1 (Wesseloo \& Read 2009).

$$
F S_{\text {mod }}=F S_{\text {best estimate }} \times \beta 1\left(X_{1}\right) \times \beta 2\left(X_{2}\right) \times \ldots \beta_{n}\left(X_{n}\right)
$$

where:

$$
\begin{aligned}
& \beta_{n}=\text { each parameter contributing to the uncertainty. } \\
& X_{n}=\text { modification factor determined probabilistically. }
\end{aligned}
$$

A probability distribution of FS is generated by repeating this calculation multiple times, 10,000 iterations were used for this project. The contributing factors used to assess PF were UCS, GSI, groundwater surface position, disturbance factor, and geological contact position. A summary of the model variations to assess these factors is provided in Table 5 . The $B 5$ geological contact position addresses the uncertainty in the boundaries between GMD and BFB and between GMD and PB. The best case scenario has been generated by shrinking the weaker units (moving the contacts) by $50 \mathrm{~m}$, while the worst case scenario has been

\begin{tabular}{|c|c|c|c|c|c|}
\hline Scenario & B1 UCS & ß2 GSI & B3 GW position & B4 D factor & B5 Geol contact position \\
\hline 1 & Mean & Mean & Best estimate & Best estimate & Best estimate \\
\hline 2 & $+1 \mathrm{SD}$ & & & & \\
\hline 3 & $-1 S D$ & & & & \\
\hline 4 & & $+1 S D$ & & & \\
\hline 5 & & -1 SD & & & \\
\hline 6 & & & Low bound & & \\
\hline 7 & & & Upper bound & & \\
\hline 8 & & & & Best case & \\
\hline 9 & & & & Worst case & \\
\hline 10 & & & & & $\begin{array}{c}\text { Best - weak units shrunk } \\
\text { by } 50 \mathrm{~m}\end{array}$ \\
\hline 11 & & & & & $\begin{array}{l}\text { Worst - weak units } \\
\text { expand by } 50 \mathrm{~m}\end{array}$ \\
\hline
\end{tabular}
created by expanding the weaker unit contacts by $50 \mathrm{~m}$.

Table 5 Models run to assess $B$ values for each contributing factor

A summary of the results is presented in Table 6 . For both the original and steepened designs, two PFs are presented. The first uses a best estimate FS as the minimum, as determined from the Phase2 and Slide deterministic models. The second uses a conservative base FS of 1.5, as indicated by 3DEC modelling, for both the original and steepened designs. In each case the base FS that has been used is underlined. 
Table 6 Summary of overall slope PF assessment for original and steepened designs

\begin{tabular}{|cccccc}
\hline \multirow{2}{*}{ Design } & \multicolumn{2}{c}{ FS } & \multicolumn{2}{c}{ Response surface } \\
\cline { 2 - 6 } & 3DEC & Phase2 & Slide & FS mean & PF\% \\
\hline Original slope design & & $2.4-2.6$ & $\underline{2.2}$ & 2.2 & 0.00 \\
\hline Original slope design & $>\underline{1.5}$ & & & 1.5 & 0.30 \\
\hline Steepened design & & $\underline{1.7-1.8}$ & 1.9 & 1.8 & 0.01 \\
\hline Steepened design & $>\underline{1.5}$ & & & 1.6 & 1.00 \\
\hline
\end{tabular}

\section{$4 \quad$ Batter steepening trial}

A trial of bi-angle batters within the GMD domains was proposed and accepted by mine management. The trial was conducted over two $30 \mathrm{~m}$ batter stacks and a larger berm was implemented between the two trial batters to maintain the feasibility inter-ramp angle of $59^{\circ}$. The trial batter configuration is shown against the original batter design in Figure 5 . The trial bi-angle batter face is developed at $75^{\circ}$ over the upper $10 \mathrm{~m}$ and vertical over the lower $20 \mathrm{~m}$. Note that the two stage presplit requires a $1 \mathrm{~m}$ step-in to enable drilling of the second stage. To facilitate the removal of the lip between the first and second stage presplit, the Stage 1 presplit was drilled with an extended subdrill of $2 \mathrm{~m}$. The bi-angle batter configuration produces an effective $83^{\circ}$ batter face angle design. The berm between the two trial batter stacks was developed at a width of $14.4 \mathrm{~m}$ to retain an inter-ramp angle of $59^{\circ}$.

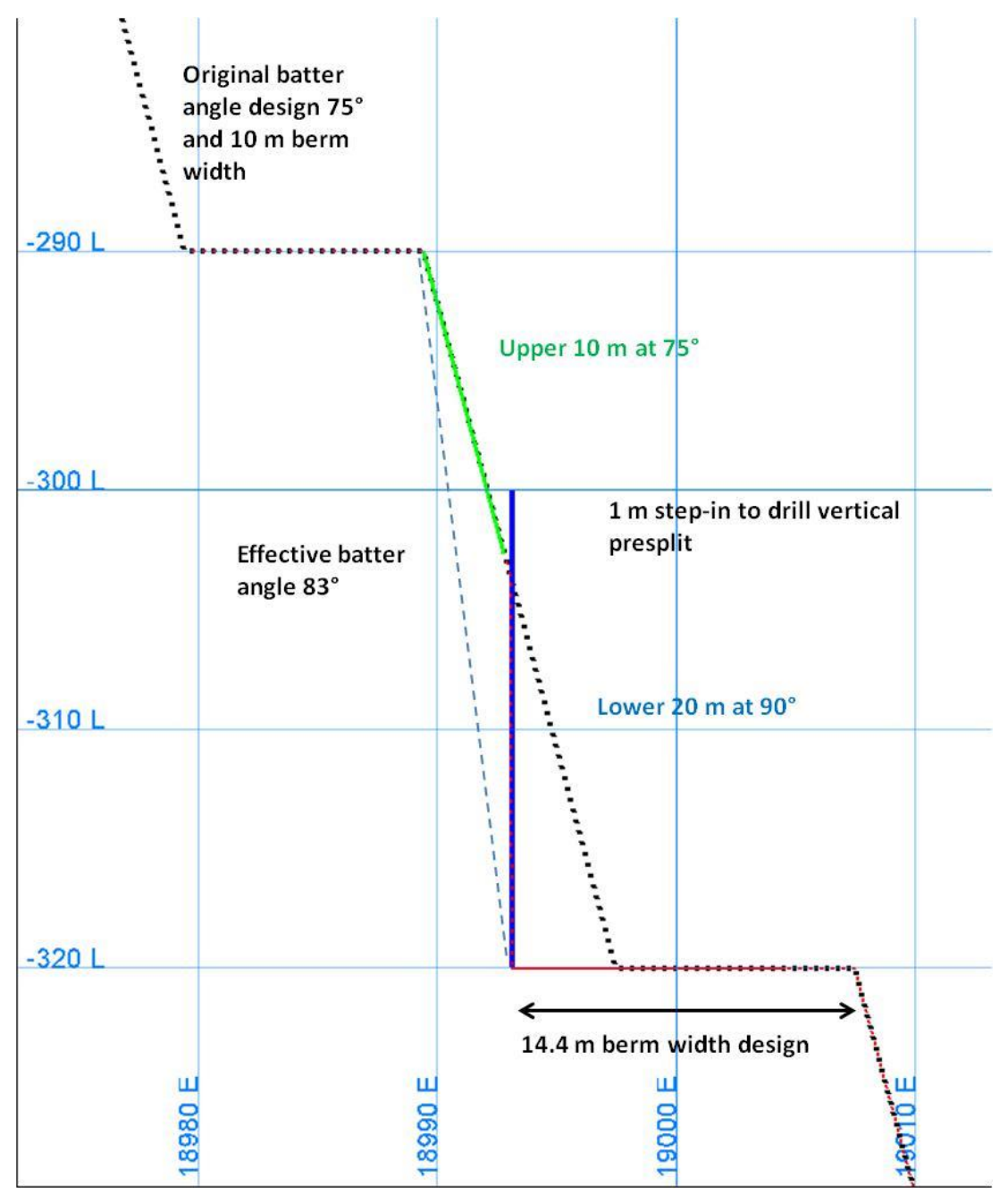

Figure 5 Trial bi-angle batter configuration versus original design 


\subsection{Batter trial results}

Sectional profiles showing the typical geometry achieved by the trial bi-angle batters are presented in Figure 6. The profiles demonstrate how well the transition zone between the 75 and $90^{\circ}$ faces has presented, compared to design. There is virtually no lip and only occasional undercuts developed at the transition.

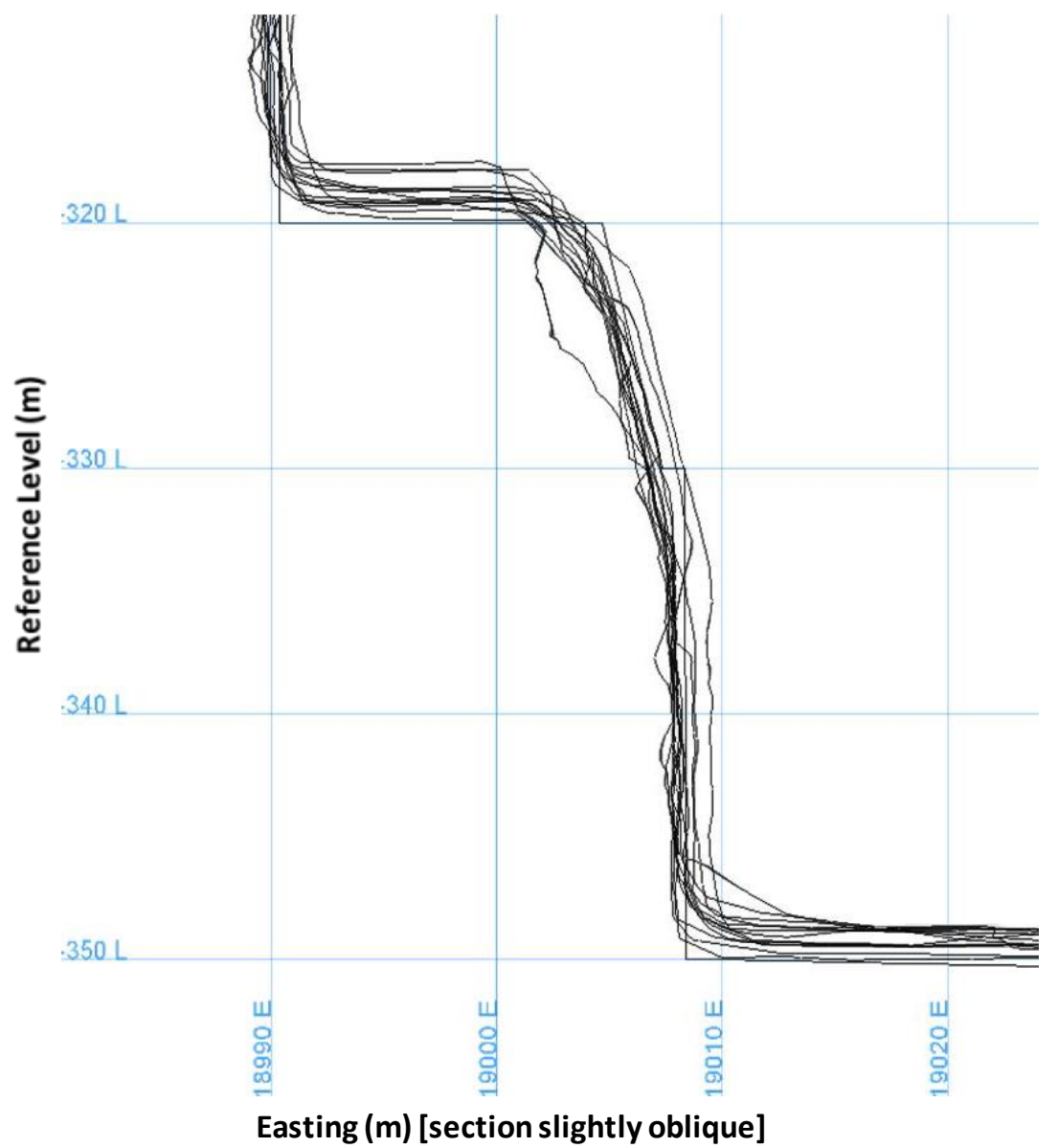

Figure 6 Trial bi-angle batter as-built geometry

Batter-berm reconciliation measurements are routinely undertaken for all newly developed slopes. Measurements of crest loss and toe flare were measured from a photogrammetric pick up against the design for sections on $5 \mathrm{~m}$ spacing. Table 7 summarises the results from reconciliation measurements of the batter steepening trial areas compared to equivalent areas of the original slope design. The effective berm widths (EBW) presented for the trial batters is based on a berm width design of $11.5 \mathrm{~m}$.

Table 7 Batter berm 50th percentile reconciliation results

\begin{tabular}{ccccccc}
\hline $\begin{array}{c}\text { Sector } \\
\text { Azimuth }\end{array}$ & \multicolumn{3}{c}{ Trial batter/berm } & \multicolumn{3}{c}{ Original batter/berm } \\
\cline { 2 - 7 } & $\begin{array}{c}\text { EBW } \\
(\mathbf{m})\end{array}$ & $\begin{array}{c}\text { Crestloss } \\
(\mathbf{m})\end{array}$ & $\begin{array}{c}\text { Toeflare } \\
(\mathbf{m})\end{array}$ & $\begin{array}{c}\text { EBW } \\
(\mathbf{m})\end{array}$ & $\begin{array}{c}\text { Crestloss } \\
(\mathbf{m})\end{array}$ & $\begin{array}{c}\text { Toeflare } \\
(\mathbf{m})\end{array}$ \\
\hline $092-096$ & 9.59 & 1.22 & 0.72 & 4.76 & 1.82 & 3.17 \\
\hline $118-122$ & 8.89 & 1.28 & 1.38 & 5.55 & 2.15 & 2.2 \\
$122-130$ & 7.32 & 2.37 & 1.88 & 6.85 & 2.1 & 1.16 \\
$135-138$ & 9.28 & 1.3 & 0.9 & 7.08 & 1.44 & 1.51 \\
\hline
\end{tabular}


The results show that a very good batter berm profile can be achieved by using the bi-angle batters. The levels of crest loss are similar to what was achieved with the original configuration, while there has been a significant improvement in the achieved toe position due to the improved drill control afforded by drilling vertical presplit holes. The predicted effective berm width for a design width of $11.5 \mathrm{~m}$ (i.e. for an IRA of $63^{\circ}$ ) is typically $8-9 \mathrm{~m}$. This is an improvement on the berm widths achieved while implementing the original configuration.

The overall performance of the bi-angle batters in the field has also been adequate to date. The design change has been embraced by the implementation crews. There has not been any noticeable change in rockfall occurrences or behaviour, although there has been an increase in ground support usage. The majority of the support increase has been on the mid bench (transition zone between 75 and $90^{\circ}$ ). For each $30 \mathrm{~m}$ batter stack mined to the steeper configuration, there has been an increase in cable bolt meterage of 15-20\% compared to base case levels on the Golden Pike west wall. KCGM's ground support program consists of bolting and meshing in specific areas. Twin strand cable bolts with a strand diameter of $15.2 \mathrm{~mm}$ and with a nominal load bearing capacity of $500 \mathrm{kN}$ are used, most commonly in 4, 6 and $8 \mathrm{~m}$ lengths. Post tensioning to $50 \mathrm{kN}$ is undertaken to provide passive support.

The bi-angle batters have also allowed an improvement of rockfall catch capacity (berm width) compared to the original design through reduced toe flare, with less presplit deviation of vertical holes and a $15 \%$ increase in the designed berm width.

\section{$5 \quad$ Updated life-of-mine design}

The steepened slope design parameters that are being implemented are summarised in Table 8 . The steepened batter design incorporates an $11.5 \mathrm{~m}$ berm producing a $63^{\circ}$ inter-ramp slope angle. These design parameters will be implemented up to a maximum inter-ramp height of $300 \mathrm{~m}$, in line with previous experience at Fimiston.

Table 8 Updated west wall slope design parameters

\begin{tabular}{ccccc}
\hline Domain rock type & BFA $\left(^{\circ}\right)$ & BH $(\mathbf{m})$ & BW $(\mathbf{m})$ & IRA $\left(^{\circ}\right)$ \\
\hline Weathered/oxide & 50 & $20(2 \times 10)$ & 10 & 37 \\
\hline GMD & $\begin{array}{c}75 \text { upper } 10 \mathrm{~m} \\
1 \text { m step-in between stages } \\
90 \text { lower } 10 \mathrm{~m}\end{array}$ & $30(3 \times 10)$ & 11.5 & 63 \\
& 75 & $30(3 \times 10)$ & 10 & 59 \\
PB & 75 & $30(3 \times 10)$ & 10 & 59 \\
\hline BFB & & & & \\
\hline
\end{tabular}

The updated LOM design pit shell steepens the west wall slope to a maximum overall slope angle of $52^{\circ}$ and the maximum depth of the pit by 50 to $720 \mathrm{~m}$. The new pit design based on these parameters adds approximately 630,000 ounces to mine reserves and approximately 12 months to the mine schedule.

\section{Conclusion}

The geotechnical project work presented within this paper supports the case for implementing a steeper batter design consisting of 75 and $90^{\circ}$ bi-angle batters, with an $11.5 \mathrm{~m}$ design berm width, for a $63^{\circ}$ inter-ramp angle within GMD domains. Since the finalisation of the steepening project, KCGM has deepened the west wall by approximately $90 \mathrm{~m}$ utilising the steepened slope parameters. The slope has continued to perform adequately as predicted.

A significant aspect to the success of the west wall steepening project has been the adoption of the $75 / 90^{\circ}$ bi-angle batters as recommended by the technical review team. This initiative allowed steepening of the 
inter-ramp slopes and improvements of the achieved berm width concurrently. The significant issue of presplit downhole deviation leading to toe flare was overcome with the drilling of vertical holes and improved drill implementation. The wall steepening project would not have been successful without having overcome this issue.

\section{Acknowledgement}

The authors acknowledge Kalgoorlie Consolidated Gold Mines and Newmont Mining Corporation for permission to publish this paper, the geotechnical review team who provided the necessary guidance and technical expertise to complete this project, and the KCGM geotechnical team for assistance throughout the project.

\section{References}

Beer, AJ \& Morrongiello, MR 2007, 'Wall Optimisation - A case study from the Fimiston Open Pit, Kalgoorlie Consolidated Gold Mines', in Y Potvin (ed.), Proceedings of the 2007 International Symposium on Rock Slope Stability in Open Pit Mining and Civil Engineering, Australian Centre for Geomechanics, Perth, pp. 403-415.

Clout, JMF, Cleghorn, JH \& Eaton, PC 1990, 'Geology of the Kalgoorlie Goldfield', in FE Hughes (ed.), Geology of the Mineral Deposits of Australia and Papua New Guinea, Australasian Institute of Mining and Metallurgy, Melbourne, pp. 411-431.

Wesseloo, J \& Read, J 2009, 'Acceptance Criteria' in Read, R \& Stacey, P (eds), Guidelines for Open Pit Slope Design, CSIRO Publishing, ch. 9, pp. 229-230.

Wines, DR 2015, Three-dimensional Numerical Slope Stability Analyses for the East and West Walls at the Superpit, unpublished company report, Itasca Australia Pty Ltd. 